(C) 2015

Biro Penerbit Planologi Undip

Volume 11 (4): 455-470 Desember 2015

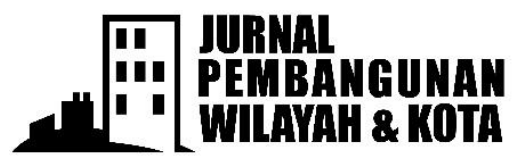

\title{
Kajian Strategi Pengembangan Zona Air Minum Prima (Zamp) Pada Kelompok Pelanggan Rumah Tangga Di Kota Bogor (Studi Kasus: Eksisting Zamp Di Kecamatan Bogor Selatan Dan Bogor Timur)
}

\author{
Nurul Ainy Gumilar ${ }^{1}$ \\ Diterima : 31 Agustus 2015 \\ Disetujui : 31 Desember 2015
}

\begin{abstract}
PDAM Tirta Pakuan as the operator of water supply in Bogor city is very attentive to provide good drinking water services to the public, especially the distribution of potable water quality through a network of piping in some areas called Zona Air Minum Prima (ZAMP). The program has been ongoing since 2004, but until now the coverage is still low compared with the total customer taps in Bogor City. Under these conditions, a research that aims to formulate development strategies in Zona Air Minum Prima (ZAMP) for groups of households customer in Bogor City is conducted. Based on the results of the survey on medium (R3-R5) and the upper middle (R6-R8) households customer in the existing ZAMP and development plans ZAMP area in Taman Yasmin, there are similar characteristics to customers in both regions indicate development potential. Assessment of customer satisfaction on aspects of quality, quantity and continuity of water in the region showed a "good" score, but an assessment of the communication aspect of PDAM is not good, especially in terms of information provided by PDAM are judged less by the customer. Based on research conducted there can be formulated several strategies, such as communication strategy through early and advanced socialization, price or tariff adjustment strategy of potable water and an additional water filter installation strategy.
\end{abstract}

Key word : Zona Air Minum Prima (ZAMP), Potable Water, Willingness to Pay (WTP), Contingent Valuation Method (CVM), Linear Regression

\section{ABSTRAK}

PDAM Tirta Pakuan selaku operator penyedia air minum di Kota Bogor sangat memperhatikan pelayanan air minum yang baik kepada masyarakat khususnya distribusi air dengan kualitas siap minum melalui jaringan perpipaan di beberapa wilayah yang disebut Zona Air Minum Prima (ZAMP). Program tersebut telah berlangsung sejak tahun 2004, namun hingga saat ini cakupannya masih rendah dibandingkan dengan total pelanggan PDAM di Kota Bogor. Berdasarkan hal tersebut maka dilakukan penelitian yang bertujuan untuk merumuskan strategi dalam pengembangan Zona Air Minum Prima (ZAMP) untuk kelompok pelanggan rumah tangga di Kota Bogor. Berdasarkan hasil survei yang telah dilakukan pada pelanggan rumah tangga menengah (R3-R5) dan menengah ke atas (R6-R8) di wilayah eksisting ZAMP dan rencana pengembangan ZAMP di Taman Yasmin, terdapat kesamaan karakteristik pelanggan di kedua wilayah yang menunjukkan adanya potensi pengembangan. Penilaian kepuasan pelanggan terhadap aspek kualitas, kuantitas dan kontinuitas air di kedua wilayah menunjukkan hasil yang "baik", tetapi penilaian terhadap aspek komunikasi PDAM kurang baik terutama dari sisi informasi yang diberikan oleh PDAM yang dinilai kurang oleh pelanggan. Berdasarkan penelitian yang dilakukan maka dapat dirumuskan rekomendasi berupa beberapa strategi, yaitu strategi komunikasi melalui sosialisasi awal dan lanjutan, strategi penyesuaian harga atau tarif air siap minum dan strategi pemasangan filter air tambahan.

Kata kunci : Zona Air Minum Prima (ZAMP), Air Siap Minum, Willingness to Pay (WTP), Contingent Valuation Method (CVM), Regresi Linier Berganda

\footnotetext{
${ }^{1}$ Kementerian Pekerjaan Umum - Badan Pendukung Pengembangan SPAM

Kontak penulis: nurul.ag@bppspam.com

2 Dosen Magister Pembangunan Wilayahdan Kota, Undip Semarang, Jawa Tengah
} 
Nurul Ainy Gumilar | Kajian Strategi Pengembangan Zona Air Minum Prima (Zamp) Pada Kelompok Pelanggan Rumah Tangga Di Kota Bogor

\section{PENDAHULUAN}

Pertumbuhan penduduk disertai dengan urbanisasi yang setiap tahun terus meningkat mengakibatkan meningkatnya kebutuhan infrastruktur khususnya sektor air minum. Oleh karena itu, Pemerintah Indonesia telah mencanangkan program pembangunan nasional dengan mengacu pada target Millennium Development Goals (MDG) yaitu mengurangi setengah dari proporsi penduduk yang tidak mempunyai akses terhadap air minum yang sehat dan sanitasi dasar pada tahun 2015 dengan harapan cakupan akses air minum nasional meningkat hingga 68,87\%. Disamping itu, sesuai dengan amanat Peraturan Pemerintah No. 16 tahun 2005 tentang Pengembangan Sistem Penyediaan Air Minum bahwa air yang didistribusikan kepada masyarakat harus memenuhi standar kualitas, kuantitas dan kontinuitas yang telah ditetapkan. Hingga saat ini masih banyak kualitas air dari jaringan perpipaan yang mengalir sampai ke masyarakat belum dapat memenuhi standar kualitas air minum, masih dalam kualitas air bersih. Salah satu wilayah perkotaan yang sangat memperhatikan pelayanan air minum yang berkualitas dan terjangkau untuk masyarakatnya adalah Kota Bogor. Kota Bogor sebagai salah satu hinterland dari DKI Jakarta yang merupakan pusat aktivitas perekonomian dan pemerintahan negara Indonesia tentunya menjadi salah satu wilayah yang berkembang sangat pesat. Salah satu program PDAM Tirta Pakuan Kota Bogor adalah penerapan Zona Air Minum Prima (ZAMP). Pengertian ZAMP sendiri adalah suatu kawasan (zona) pelayanan PDAM dimana kualitas dari air yang didistribusikan kepada pelanggan di daerah tersebut dapat diminum secara langsung dan sudah sesuai dengan standar kualitas air minum yang ditetapkan melalui Peraturan Menteri Kesehatan No. 492 Tahun 2010 tentang Persyaratan Kualitas Air Minum. Pelaksanaan Zona Air Minum Prima (ZAMP) di Kota Bogor sendiri dari tahun 2004 hingga saat ini baru mencapai 8.779 Sambungan Rumah (SR). Jumlah pelanggan ZAMP tersebut masih cukup kecil yaitu sekitar 7,4\% dari total sambungan pelanggan PDAM.

Rendahnya tingkat pengembangan ZAMP di wilayah Kota Bogor dapat disebabkan oleh faktorfaktor internal maupun eksternal. Salah satu faktor internal yang mempengaruhi adalah kondisi jaringan pipa distribusi PDAM Tirta Pakuan yang sudah tua. Terdapat sekitar 60\% jaringan pipa distribusi PDAM yang kondisinya sudah menurun sehingga menimbulkan banyak kebocoran. Hal ini terlihat pula dari tingginya nilai kehilangan air/air tak berekening (Non-Revenue Water) di Kota Bogor sebesar 35,33\% (sumber: PDAM Tirta Pakuan). Selain kondisi jaringan perpipaan yang sudah menurun tentunya masih banyak faktor-faktor lain yang mempengaruhi rendahnya pengembangan ZAMP di wilayah Kota Bogor yang perlu dianalisis lebih lanjut.

Adapun air hasil produksi dari PDAM Tirta Pakuan sendiri saat ini sudah memenuhi standar kualitas air minum. Pada awal tahun 2014, PDAM Tirta Pakuan telah memperoleh sertifikat ISO untuk penyediaan pengolahan dan distribusi pelayanan air siap minum. Namun dikarenakan sebagian besar jaringan pipa distribusi PDAM kondisinya sudah tua sehingga distribusi air dengan kualitas layak minum tidak dapat dilakukan ke seluruh sambungan pelanggan PDAM. Investasi untuk pengembangan ZAMP sendiri cukup besar sedangkan tarif yang dikenakan kepada pelanggan ZAMP sama seperti tarif pelanggan PDAM pada umumnya (tidak dikenakan tarif khusus). Rata-rata pelanggan rumah tangga ZAMP ini berada pada kelompok tarif pelanggan rumah tangga menengah ke atas yaitu R3 sampai dengan R8 dalam struktur tarif PDAM Tirta Pakuan.

Seiring dengan perkembangan pengelolaan air minum di Kota Bogor, konsep pengembangan ZAMP sejak tahun 2011 mulai mengarah pada wilayah jaringan perpipaan di setiap zona. Target yang ingin dicapai oleh PDAM Tirta Pakuan dalam waktu dekat adalah di wilayah konsumen terbanyak yaitu di Zona 4 sebesar 69.116 sambungan langsung. Akan tetapi sampai dengan 
JPWK 11 (4) Nurul Ainy Gumilar | Kajian Strategi Pengembangan Zona Air Minum Prima (Zamp) Pada Kelompok Pelanggan Rumah Tangga Di Kota Bogor

tahun 2014 ini target tersebut belum tercapai, pengembangan ZAMP di wilayah Zona 4 PDAM Tirta Pakuan baru mencakup beberapa kawasan perumahan saja yaitu Taman Yasmin Sektor 6 dan Villa Bogor Indah. Sedangkan Zona 4 sendiri saat ini merupakan wilayah dengan pengembangan perumahan dan permukiman yang cukup pesat sesuai dengan arahan struktur ruang di Kota Bogor. Potensi untuk pengembangan ZAMP di wilayah ini pun cukup besar terutama untuk wilayah di sekitar jaringan eksisting ZAMP yang sudah ada seperti di Perumahan Taman Yasmin.

Berdasarkan uraian tersebut, maka permasalahan yang akan dibahas dalam penelitian ini adalah : Bagaimana strategi yang tepat untuk mengembangkan Zona Air Minum Prima (ZAMP) pada pelanggan rumah tangga berdasarkan karakteristik pelanggan dan penerapan pelayanan air siap minum oleh PDAM Tirta Pakuan Kota Bogor?

Adapun tujuan yang ingin dicapai dari penelitian ini adalah merumuskan strategi yang dapat dijadikan sebagai rekomendasi dalam pengembangan Zona Air Minum Prima (ZAMP) untuk kelompok pelanggan rumah tangga di Kota Bogor. Sasaran untuk mencapai tujuan yang dimaksud adalah sebagai berikut:

1. Mengidentifikasi karakteristik pelanggan rumah tangga PDAM di Zona Air Minum Prima (ZAMP) dan wilayah rencana pengembangan ZAMP (Perumahan Taman Yasmin).

2. Menganalisis kondisi pelayanan PDAM melalui penilaian kepuasan pelanggan dan penerapan pelayanan air minum di wilayah eksisting ZAMP dan Perumahan Taman Yasmin.

3. Menganalisis besarnya nilai kesediaan membayar/willingness to pay (WTP) pelanggan terhadap tambahan manfaat air siap minum dan faktor-faktor yang mempengaruhinya serta rencana pengembangan ZAMP di wilayah Perumahan Taman Yasmin.

4. Merumuskan strategi pengembangan Zona Air Minum Prima (ZAMP) pada pelanggan rumah tangga di Kota Bogor.

\section{METODE PENELITIAN}

\section{Pendekatan Penelitian}

Penelitian ini menggunakan pendekatan deduktif dengan metode kuantitatif dan diperdalam dengan pendekatan induktif dengan metode kualitatif. Metode penelitian gabungan atau mix method dalam penelitian ini menggunakan metode kuantitatif sebagai pegangan utama yang dilengkapi dengan metode kualitatif untuk lebih memperdalam lagi hasil temuan serta agar dapat saling melengkapi satu sama lain. Pendekatan yang digunakan tentunya berkaitan dengan permasalahan yang diangkat yaitu ingin mengetahui karakteristik dan permasalahan yang terdapat pada pelanggan rumah tangga di eksisting ZAMP, mencari besaran keinginan atau kesediaan membayar (WTP) lebih dari tarif air saat ini sebagai respon atas tambahan manfaat yang diperoleh dari pengembangan kualitas air siap minum dan merumuskan strategi untuk pengembangan ZAMP di wilayah Kota Bogor.

\section{Teknik dan Proses Analisis}

Metode utama yang menjadi acuan dalam penelitian ini adalah metode kuantitatif dengan menggunakan beberapa teori dan variabel diantaranya teori karakteristik pelanggan rumah tangga untuk air minum dan pemantauan penerapan eksisting air minum, analisis Willingness to Pay (WTP) dengan menggunakan Contingent Valuation Method (CVM). Sedangkan metode kualitatif yang digunakan dalam penelitian ini adalah deskriptif kualitatif dengan teknik 
Nurul Ainy Gumilar | Kajian Strategi Pengembangan Zona Air Minum Prima (Zamp) Pada Kelompok Pelanggan Rumah Tangga Di Kota Bogor

wawancara untuk mengumpulkan data-data tambahan yang diperlukan dalam melengkapi analisis deskriptif kuantitatif sebelumnya.

Metode Deskriptif Kuantitatif dilakukan untuk mengetahui karakteristik pelanggan rumah tangga pada eksisting ZAMP di Kecamatan Bogor Selatan dan Bogor Timur serta di wilayah rencana pengembangan ZAMP di Perumahan Taman Yasmin. Data diperoleh melalui kuesioner dan diperkuat dengan wawancara dan observasi di lapangan. Adapun beberapa variabel dan indikator yang digunakan untuk analisis identifikasi karakteristik sosial ekonomi dan konsumsi air minum pelanggan rumah tangga antara lain adalah usia, jenis kelamin, pendidikan terakhir, pekerjaan, penghasilan, jumlah anggota keluarga, luas bangunan tempat tinggal, rata-rata pemakaian air/bulan dan rata-rata pembayaran rekening air/bulan.

Analisis Pembobotan digunakan untuk memudahkan pengolahan data agar lebih sederhana dan sistematis. Data yang diperoleh dari hasil survei lapangan dikelompokkan dan diubah menjadi angka berkelompok. Untuk pengukur data diubah menjadi penilaian, dihitung dari nilai yang paling negatif hingga positif yang kemudian diberi angka-angka sebagai symbol perhitungan. Hal ini sesuai dengan yang dijelaskan pada skala Likert, bahwa penilaian dilakukan dari angka yang rendah untuk yang paling negatif sampai angka yang tinggi untuk yang paling positif (Sarwono, 2006). Rentang skor yang digunakan dalam penelitian ini terdiri dari 4 kelas yaitu Buruk, Kurang Baik, Cukup dan Baik dengan masing-masing menggunakan 4 jenjang skor yaitu 1, 2, 3 dan 4. Skor tersebut digunakan untuk menilai tingkat kepuasan pelanggan terhadap pelayanan air minum yang diberikan oleh PDAM di wilayah eksisting ZAMP dan Taman Yasmin yaitu kualitas air, kuantitas air, kontinuitas air dan komunikasi PDAM.

Analisis Kesediaan Membayar/Willingness to Pay (WTP) dalam penelitian ini dilakukan untuk mengidentifikasi seberapa besar keinginan membayar dari pelanggan rumah tangga terhadap penyediaan air siap minum yang diberikan oleh PDAM. Dalam menganalisis nilai WTP ini menggunakan metode Contingent Valuation Method (CVM) yang terdiri dari beberapa tahapan (Hanley dan Spash, 1993) yaitu membuat pasar hipotetik (Setting up the Hypotetical Market), mendapatkan penawaran besarnya nilai WTP (Obtaining Bids), memperkirakan nilai rata-rata WTP (Calculating Average WTP), dan mengevaluasi penggunaan CVM. Selanjutnya dilakukan analisis fungsi WTP untuk mengetahui faktor-faktor yang mempengaruhi WTP responden. Model yang digunakan adalah model regresi linier berganda. Adapun fungsi WTP yang digunakan dalam penelitian ini terdiri dari variabel independen usia pelanggan, jumlah kebutuhan air dalam rumah tangga, penilaian terhadap kualitas air, tingkat pendidikan responden dan pendapatan rumah tangga.

Dalam merumuskan strategi pengembangan Zona Air Minum Prima (ZAMP) pada pelanggan rumah tangga di Kota Bogor terdapat beberapa variabel yang diperlukan seperti yang telah dijelaskan sebelumnya yaitu karakteristik pelanggan, kepuasan pelanggan dan penerapan air siap minum/ZAMP serta willingness to pay (WTP)/kesediaan membayar air siap minum. Variabel karakteristik pelanggan diperlukan dalam melihat adanya kemiripan karakteristik antara wilayah eksisting dan wilayah perencanaan untuk mengidentifikasi potensi pengembangan ZAMP. Selanjutnya variabel kepuasan pelanggan dan evaluasi penerapan ZAMP digunakan untuk menilai pelayanan air minum (supply) yang telah diberikan oleh PDAM selama ini. Willingness to pay digunakan untuk mengetahui besarnya kesediaan pelanggan memberikan imbalan atas peningkatan kualitas air yang diberikan oleh PDAM. 
JPWK 11 (4) Nurul Ainy Gumilar | Kajian Strategi Pengembangan Zona Air Minum Prima (Zamp) Pada Kelompok Pelanggan Rumah Tangga Di Kota Bogor

\section{GAMBARAN UMUM}

Program ZAMP di wilayah Kota Bogor pada awalnya dilaksanakan di Perumahan Pakuan Tajur sebagai pilot project. Pengembangan ZAMP terus meningkat setiap tahunnya. Sampai dengan tahun 2013, ZAMP di Kota Bogor telah mencapai 13 titik zona dengan jumlah total sambungan langsung sebesar 8.779 SR. Mayoritas pelanggan ZAMP tersebut adalah kawasan perumahan menengah ke atas yang berada di wilayah Kecamatan Bogor Selatan dan Bogor Timur. Oleh karena itu dalam penelitian akan fokus membahas pelanggan ZAMP rumah tangga di wilayah tersebut. Lokasi eksisting ZAMP PDAM Tirta Pakuan Kota Bogor yang akan difokuskan dalam penelitian ini adalah perumahan Intan Pakuan, Pakuan Tajur, Montecarlo, Griya Katulampa, Teras Hijau, Cipaku, Cipaku BTN, Cipaku Perkesa, Cipaku Perumda, dan Cipaku PWI (Gambar.1). Lokasi-lokasi perumahan tersebut terletak di Kelurahan Katulampa, Tajur, Pakuan, Sindangrasa dan Cipaku.

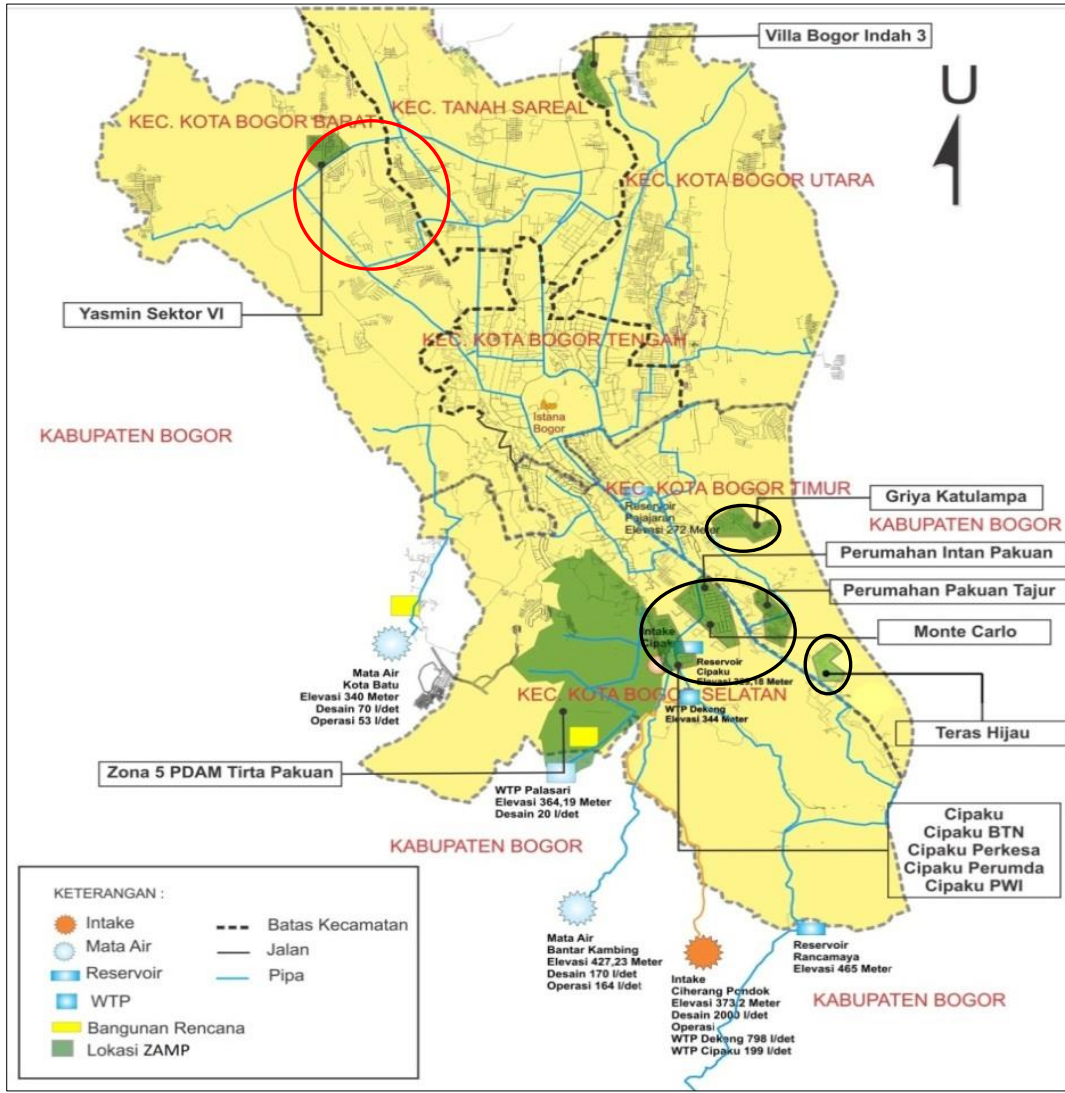

Sumber: PDAM Tirta Pakuan Kota Bogor dan Analisis Penulis, 2014

GAMBAR 1

PETA LOKASI EKSISTING DAN RENCANA PENGEMBANGAN ZAMP PDAM TIRTA PAKUAN KOTA BOGOR

Pelanggan rumah tangga di lokasi perumahan tersebut yang terdiri dari pelanggan rumah tangga golongan tarif R3 sampai dengan R8 dalam penelitian ini dikelompokkan kedalam dua kategori yaitu rumah tangga menengah ( $\left.\mathrm{R}_{3}-\mathrm{R} 5\right)$ dan rumah tangga menengah ke atas (R6 R8). Adapun jumlah keseluruhan pelanggan rumah tangga di lokasi penelitian tersebut adalah 2.205 Sambungan Rumah (SR) yang terdiri dari 1.504 SR rumah tangga menengah dan 701 SR rumah tangga menengah ke atas. Selain menganalisis kondisi pelayanan di wilayah eksisting ZAMP, penelitian ini juga akan melihat potensi pengembangan ZAMP di wilayah perencanaan 
Nurul Ainy Gumilar | Kajian Strategi Pengembangan Zona Air Minum Prima (Zamp) Pada Kelompok Pelanggan Rumah Tangga Di Kota Bogor

yaitu di Perumahan Taman Yasmin, Kecamatan Bogor Barat. Area Perumahan Taman Yasmin ini sangat luas hingga mencakup tiga wilayah kelurahan yaitu Kelurahan Cilendek Barat, Cilendek Timur dan Curugmekar. Sektor 2 merupakan sektor yang paling luas di Perumahan Taman Yasmin. Sedangkan sektor 4 memiliki luas paling kecil

Terdapat tiga alasan dalam pemilihan wilayah perencanaan pengembangan ZAMP ini. Alasan yang pertama adalah lokasi perumahan yang berada di Zona 4 wilayah pelayanan PDAM Tirta Pakuan Kota Bogor (target pengembangan ZAMP sesuai rencana PDAM). Kedua, karena sudah adanya wilayah penerapan ZAMP pada salah satu sektor di kawasan perumahan ini yaitu di Taman Yasmin sektor VI. Ketiga, karena kawasan perumahan ini memiliki klasifikasi kelompok rumah tangga yang cukup bervariasi sehingga dianggap dapat mewakili (representatif) terhadap kelompok rumah tangga menengah dan menengah ke atas yang akan dikaji dalam penelitian ini.

\section{KAJIAN TEORI}

Air minum menurut Joko (2010) adalah air minum rumah tangga yang melalui proses pengolahan atau tanpa proses pengolahan yang memenuhi syarat kesehatan dan dapat langsung diminum. Lebih spesifik lagi pengertian air minum berdasarkan Peraturan Menteri Kesehatan RI 492/Menkes/Per/IV/2010 tentang Syarat-syarat dan Pengawasan Kualitas Air Minum, yang dimaksud dengan air minum adalah air yang melalui proses pengolahan atau tanpa proses pengolahan yang memenuhi syarat kesehatan dan dapat langsung diminum, yaitu: persyaratan bakteriologis, persyaratan kimiawi, persyaratan radioaktivitas, dan persyaratan fisik.

Penyediaan air minum adalah kegiatan menyediakan air minum untuk memenuhi kebutuhan masyarakat agar mendapatkan kehidupan yang sehat, bersih dan produktif, sedangkan sistem penyediaan air minum yang selanjutnya disebut SPAM merupakan satu kesatuan sistem fisik (teknik) dan non fisik dari prasarana dan sarana air minum Joko (2010). Sistem penyediaan air minum yang baik bertujuan untuk:

1. Menyediakan air yang kualitasnya aman dan sehat bagi pemakainya, individu maupun masyarakat,

2. Menyediakan air yang memadai kuantitasnya, dan

3. Menyediakan air secara kontinyu, mudah dan murah untuk menunjang hygiene perseorangan maupun rumah tangga.

Terdapat tiga komponen utama dalam sistem penyediaan air minum (sistem PDAM) dengan komposisi yaitu: Sumber Air (water resources), Sistem Produksi dan Sistem Distribusi. Sistem distribusi bertujuan untuk mengalirkan air yang telah memenuhi pesyaratan baku mutu air ke konsumen. Dalam Dep.PU (Petunjuk Teknis Pengelolaan Sistem Penyediaan Air Minum Perkotaan, 1998), sistem distribusi perlu diperhatikan agar terdapat :

- Tekanan minimum yang sampai pada konsumen/pelanggan adalah 5 meter kolom air ( $5 \mathrm{mka}$ ) sehingga dapat mengalir dengan kuantitas yang direncanakan.

- Kuantitas yang sesuai dengan kebutuhan kategori kota kecil adalah 130 liter/orang/hari.

- Kuantitas pengaliran, yaitu air mengalir setiap saat (tanpa terputus selama 24 jam) sehingga dapat memuaskan konsumen.

Sedangkan Zona Air Minum Prima (ZAMP) merupakan zona khusus yang ditetapkan oleh PDAM untuk layanan air siap minum. Dengan demikian air yang didistribusikan ke kawasan tersebut sudah memenuhi standar kualitas kesehatan (Peraturan Menteri Kesehatan No. 492 Tahun 2010 
JPWK 11 (4) Nurul Ainy Gumilar | Kajian Strategi Pengembangan Zona Air Minum Prima (Zamp) Pada Kelompok Pelanggan Rumah Tangga Di Kota Bogor

tentang Persyaratan Kualitas Air Minum) dan aman untuk langsung diminum. Sebelum menentukan wilayah untuk ZAMP, terdapat beberapa kriteria yang harus diperhatikan, yaitu:

1. Bidang Teknik

a. Jaringan pipa memenuhi syarat

- Pengaliran 24 jam

- Ada alternatif suplai

- Tekanan 1,5 bar

- Usia jaringan relatif baru

- Sistem Instalasi Plumbing konsumen memenuhi syarat

b. Peta dan data jaringan lengkap dan selalu diperbaharui

c. Suplai sudah memenuhi syarat air minum

d. Zona dapat terisolasi

2. Bidang Manajemen

- $\quad$ Sistem manajemen baik

- Full cost recovery

- Kualitas, kuantitas, kontinuitas

- Aspek legal

3. Bidang Komunikasi

a. Komunikasi Internal

- Sumber Daya Manusia (SDM) yang profesional

- Strategi pelayanan

- Jaringan komunikasi dengan media

b. Komunikasi Eksternal

- Sosial ekonomi pelanggan

- Perilaku pelanggan

- Hubungan dengan stakeholder

- Adanya kelompok/forum pelanggan

- Tingkat pengaduan rendah

Dasar penetapan tarif air mengacu Peraturan Menteri Dalam Negeri Nomor 23 tahun 2006 tentang Pedoman Teknis dan Tata Cara Pengaturan Tarif Air Minum pada Perusahaan Daerah Air Minum. Tarif memenuhi prinsip keterjangkauan apabila pengeluaran rumah tangga untuk memenuhi standar kebutuhan pokok air minum tidak melampaui $4 \%$ dari pendapatan masyarakat pelanggan. Pedoman penentuan tarif air minum, pola tarif air minum PDAM di Indonesia menggunakan perhitungan tarif progresif dan diskriminatif. Melalui peraturan tersebut, tarif air yang diberlakukan PDAM memiliki pola berikut:

a. Besaran tarif air $/ \mathrm{m}^{3}$ semakin tinggi akan dikenakan pada pemakaian air yang semakin banyak (tarif progresif). Tarif air $/ \mathrm{m}^{3}$ untuk pemakaian air $10 \mathrm{~m}^{3}$ pertama akan lebih rendah daripada Tarif air/ $\mathrm{m}^{3}$ untuk pemakaian air $10 \mathrm{~m}^{3}$ kedua.

b. Tarif air $/ \mathrm{m}^{3}$ akan dikenakan lebih tinggi pada pelanggan yang memanfaatkan air untuk kebutuhan komersial atau pada pelanggan yang memiliki kemampuan finansial "tinggi" (tarif diskriminatif).

Willingness to Pay (WTP) adalah kesediaan pengguna untuk mengeluarkan imbalan atas barang atau jasa yang diterimanya. Menurut Hanley dan Spash (1993), Willingness to Pay atau kesediaan untuk membayar adalah kesediaan individu untuk membayar terhadap suatu kondisi lingkungan atau penilaian terhadap sumberdaya alam dan jasa alami dalam rangka memperbaiki kualitas lingkungan. Contingent Valuation Method (CVM) adalah metode teknik survei untuk menanyakan kepada penduduk tentang nilai atau harga yang mereka berikan terhadap komoditi yang tidak memiliki pasar seperti barang lingkungan (Yakin, 1997). CVM menggunakan pendekatan secara 
Nurul Ainy Gumilar | Kajian Strategi Pengembangan Zona Air Minum Prima (Zamp) Pada Kelompok Pelanggan Rumah Tangga Di Kota Bogor

JPWK 11 (4)

langsung yang pada dasarnya menanyakan kepada masyarakat berapa besarnya keinginan membayar dari masyarakat atau Willingness to Pay (WTP) untuk manfaat tambahan dari barang lingkungan, perbaikan lingkungan, fasilitas dan barang non-pasar.

Penyediaan air minum merupakan jenis pelayanan barang dan jasa. Kualitas pelayanan memiliki hubungan erat dengan kepuasan pelanggan. Menurut Philip Kotler (dalam Tjiptono, 2003:102), kepuasan merupakan tingkat perasaan dimana seseorang menyatakan hasil perbandingan atas kinerja produk/jasa yang diterima dengan yang diharapkan. Kepuasan dan ketidakpuasan pelanggan akan suatu produk sebagai akhir dari suatu proses penjualan memberikan dampak tersendiri kepada perilaku pelanggan terhadap produk tersebut. Pada penelitian ini kepuasan pelanggan terhadap penyelenggaraan pelayanan air minum yang dikaji hanya terkait pada aspek kualitas, kuantitas, kontinuitas pelayanan air minum dan komunikasi PDAM terhadap pelanggan rumah tangga yang berada di Zona Air Minum Prima (ZAMP).

Dalam merumuskan strategi untuk pengembangan Zona Air Minum Prima (ZAMP), perlu memperhatikan beberapa kriteria sesuai dengan yang telah disebutkan dalam SOP ZAMP sebelumya, yaitu bidang teknis, bidang manajemen, dan bidang komunikasi. Penelitian ini akan menganalisis beberapa aspek dari masing-masing bidang tersebut yaitu bidang teknis terkait aspek kualitas (suplai sudah memenuhi syarat air minum), kuantitas (tekanan yang cukup besar; 1,5 bar), kontinuitas (pengaliran 24 jam). Sedangkan dari bidang komunikasi yang diteliti adalah aspek komunikasi eksternal yang berhubungan dengan sosial ekonomi pelanggan, perilaku pelanggan, hubungan dengan stakeholder (PDAM) dan lain-lain. Selain melihat kriteria tersebut, kesediaan pelanggan dalam mengkonsumsi dan memberikan imbalan atas peningkatan kualitas air siap minum pun perlu untuk dianalisis.

\section{ANALISIS DAN PEMBAHASAN}

\section{Analisis Karakteristik Pelanggan PDAM}

Hasil analisis terhadap karakteristik sosial ekonomi dan konsumsi air PDAM pada pelanggan rumah tangga menengah (R3-R5) di wilayah eksisting ZAMP dan Taman Yasmin (wilayah rencana pengembangan), memperlihatkan beberapa kesamaan karakteristik yang menunjukkan adanya potensi untuk pengembangan ZAMP di wilayah perencanaan. Kesamaan karakteristik tersebut dapat dilihat pada tabel perbandingan berikut ini.

TABEL 1

KOMPARASI HASIL ANALISIS KARATERISTIK PELANGGAN PDAM RUMAH TANGGA MENENGAH (R3-R5)

\begin{tabular}{|c|c|c|c|}
\hline \multirow[b]{2}{*}{$\begin{array}{l}\text { Karakteristik } \\
\text { Dominan }\end{array}$} & \multicolumn{2}{|c|}{ Wilayah } & \multirow[b]{2}{*}{ Hasil Analisis } \\
\hline & $\begin{array}{l}\text { Eksisting } \\
\text { ZAMP }\end{array}$ & $\begin{array}{c}\text { Taman } \\
\text { Yasmin } \\
\end{array}$ & \\
\hline \multicolumn{3}{|c|}{ Karakteristik Sosial Ekonomi } & \multirow{5}{*}{$\begin{array}{l}\text { Responden untuk kategori pelanggan rumah } \\
\text { tangga menengah ini didominasi oleh perempuan } \\
\text { dengan rentang usia } 41-50 \text { th untuk wilayah } \\
\text { eksisting dan } 31-40 \text { th di Taman Yasmin. } \\
\text { Karakteristik sosial ekonomi pelanggan rumah } \\
\text { tangga menengah (R3-R5) di wilayah eksisting } \\
\text { ZAMP dan Taman Yasmin sama-sama } \\
\text { menunjukkan bahwa jumlah anggota keluarga } \\
\text { mayoritas adalah } 4 \text { orang dengan pekerjaan }\end{array}$} \\
\hline Usia & $41-50$ th & $31-40$ th & \\
\hline Jenis Kelamin & Perempuan & Perempuan & \\
\hline $\begin{array}{c}\text { Jumlah Anggota } \\
\text { Keluarga }\end{array}$ & 4 orang & 4 orang & \\
\hline Pekerjaan KK & & & \\
\hline
\end{tabular}


JPWK 11 (4) Nurul Ainy Gumilar | Kajian Strategi Pengembangan Zona Air Minum Prima (Zamp) Pada Kelompok Pelanggan Rumah Tangga Di Kota Bogor

\begin{tabular}{|c|c|c|c|}
\hline & $\begin{array}{c}\text { Pegawai } \\
\text { Swasta }\end{array}$ & $\begin{array}{l}\text { Pegawai } \\
\text { Swasta }\end{array}$ & \multirow{7}{*}{$\begin{array}{l}\text { kepala keluarga (KK) sebagai pegawai swasta. } \\
\text { Sedangkan tingkat pendidikan KK yang dominan } \\
\text { untuk wilayah eksisting ZAMP adalah SMA dan } \\
\text { Taman Yasmin didominasi oleh S1/D3. } \\
\text { Penghasilan rata-rata rumah tangga di kedua } \\
\text { wilayah sedikit berbeda, yaitu sekitar Rp } 2,6-4 \\
\text { juta untuk wilayah eksisting dan Rp 5,6-7,5 juta } \\
\text { untuk wilayah Taman Yasmin. Sedangkan luas } \\
\text { bangunan tempat tinggal walaupun sedikit } \\
\text { berbeda tetapi tetap didominasi oleh tipe } \\
\text { bangunan yang termasuk kedalam kategori } \\
\text { rumah tangga menengah yaitu }>54 \text { m }{ }^{2} \text { s.d } \leq 100 \\
\text { m². } \\
\text { Terdapat kesamaan dalam karakteristik } \\
\text { konsumsi air PDAM di kedua wilayah yaitu jumlah } \\
\text { konsumsi air PDAM/bulan rata-rata antara } 16-20 \\
\text { m3. Namun dengan rata-rata kisaran tarif } \\
\text { pembayaran yang sedikit berbeda. Di wilayah } \\
\text { eksisting ZAMP, tarif berkisar antara Rp } 50-99 \\
\text { ribu sedangkan di Taman Yasmin sekitar Rp } 100- \\
\text { 199 ribu. }\end{array}$} \\
\hline $\begin{array}{l}\text { Pendidikan } \\
\text { Terakhir KK }\end{array}$ & SMA & $\mathrm{S}_{1} / \mathrm{D}_{3}$ & \\
\hline $\begin{array}{l}\text { Penghasilan } \\
\text { RT/bulan }\end{array}$ & $\begin{array}{l}\text { Rp 2,6 - } 4 \\
\text { juta }\end{array}$ & $\begin{array}{l}\text { Rp 5,6 - 7,5 } \\
\text { juta }\end{array}$ & \\
\hline $\begin{array}{l}\text { Luas Bangunan } \\
\text { Tempat Tinggal }\end{array}$ & $\begin{array}{c}>54 \mathrm{~m}^{2}-\leq \\
70 \mathrm{~m}^{2}\end{array}$ & $\begin{array}{c}>70 \mathrm{~m}^{2}-\leq \\
100 \mathrm{~m}^{2}\end{array}$ & \\
\hline \multicolumn{3}{|c|}{ Karakteristik Konsumsi Air PDAM } & \\
\hline $\begin{array}{l}\text { Pembayaran Air } \\
\text { PDAM/Bulan }\end{array}$ & $\begin{array}{l}\text { Rp } 50-99 \\
\text { ribu }\end{array}$ & $\begin{array}{l}\text { Rp } 100- \\
199 \text { ribu }\end{array}$ & \\
\hline $\begin{array}{l}\text { Konsumsi air } \\
\text { PDAM/Bulan }\end{array}$ & $16-20 \mathrm{~m}^{3}$ & $16-20 \mathrm{~m}^{3}$ & \\
\hline
\end{tabular}

Sumber: Analisis Penulis, 2015

Sedangkan pada pelanggan PDAM kategori rumah tangga menengah ke atas (R6-R8) di wilayah eksisting ZAMP dan Taman Yasmin terdapat lebih banyak kesamaan karakteristik dibandingkan dengan kategori rumah tangga menengah ( $\left.\mathrm{R}_{3}-\mathrm{R}_{5}\right)$. Kesamaan tersebut dapat dilihat pada tabel 2 berikut.

TABEL 2

KOMPARASI HASIL ANALISIS KARATERISTIK PELANGGAN PDAM RUMAH TANGGA MENENGAH KE ATAS (R6-R8)

\begin{tabular}{|c|c|c|c|}
\hline \multirow[b]{2}{*}{$\begin{array}{c}\text { Karakteristik } \\
\text { Dominan }\end{array}$} & \multicolumn{2}{|c|}{ Wilayah } & \multirow[b]{2}{*}{ Hasil Analisis } \\
\hline & \begin{tabular}{|c|}
$\begin{array}{c}\text { Eksisting } \\
\text { ZAMP }\end{array}$ \\
\end{tabular} & \begin{tabular}{c|c|} 
Taman \\
Yasmin
\end{tabular} & \\
\hline \multicolumn{3}{|c|}{ Karakteristik Sosial Ekonomi } & \multirow{8}{*}{$\begin{array}{l}\text { Dari hasil survei yang dilakukan terhadap } \\
\text { pelanggan rumah tangga menengah ke atas } \\
\text { (R6-R8), responden didominasi oleh jenis } \\
\text { kelamin laki-laki usia } 31-40 \text { th di wilayah Taman } \\
\text { Yasmin dan perempuan usia } 51 \text { - } 60 \text { th di wilayah } \\
\text { eksisting ZAMP. } \\
\text { Karakteristik sosial ekonomi pelanggan di kedua } \\
\text { wilayah tersebut didominasi oleh beberapa } \\
\text { kesamaan yaitu jumlah anggota keluarga } 5 \\
\text { orang, pendidikan terakhir KK adalah S1/D3 dan } \\
\text { penghasilan rata-rata RT/bulan > Rp } 10 \text { juta. } \\
\text { Demikian halnya dengan karakteristik konsumsi } \\
\text { air PDAM yang didominasi oleh rata-rata } \\
\text { pembayaran air PDAM/bulan sekitar Rp } 200- \\
299 \text { ribu dan jumlah konsumsi air PDAM/bulan } \\
\text { rata-rata sebesar } 21-25 \mathrm{~m}^{3} \text {. }\end{array}$} \\
\hline Usia & $51-60$ th & $31-40$ th & \\
\hline Jenis Kelamin & Perempuan & Laki-laki & \\
\hline $\begin{array}{c}\text { Jumlah Anggota } \\
\text { Keluarga }\end{array}$ & 5 orang & 5 orang & \\
\hline Pekerjaan KK & $\begin{array}{l}\text { Wiraswasta/ } \\
\text { Pengusaha }\end{array}$ & $\begin{array}{l}\text { Pegawai } \\
\text { Swasta }\end{array}$ & \\
\hline $\begin{array}{l}\text { Pendidikan } \\
\text { Terakhir KK }\end{array}$ & $\mathrm{S}_{1} / \mathrm{D}_{3}$ & $\mathrm{~S} 1 / \mathrm{D} 3$ & \\
\hline $\begin{array}{l}\text { Penghasilan } \\
\text { RT/bulan }\end{array}$ & $\begin{array}{l}>\operatorname{Rp} 10 \\
\text { juta }\end{array}$ & $\begin{array}{l}>\text { Rp } 10 \\
\text { juta }\end{array}$ & \\
\hline $\begin{array}{l}\text { Luas Bangunan } \\
\text { Tempat Tinggal }\end{array}$ & $>150 \mathrm{~m} 2$ & $\begin{array}{c}>120 \mathrm{~m} 2-\leq \\
150 \mathrm{~m} 2\end{array}$ & \\
\hline
\end{tabular}


Nurul Ainy Gumilar | Kajian Strategi Pengembangan Zona Air Minum Prima (Zamp) Pada Kelompok Pelanggan Rumah Tangga Di Kota Bogor

\begin{tabular}{|c|c|c|c|}
\hline \multicolumn{3}{|c|}{ Karakteristik Konsumsi Air PDAM } & Sedangkan karakteristik pekerjaan kepala \\
\hline $\begin{array}{l}\text { Pembayaran Air } \\
\text { PDAM/Bulan }\end{array}$ & $\begin{array}{l}\text { Rp } 200- \\
299 \text { ribu }\end{array}$ & $\begin{array}{l}\text { Rp } 200- \\
299 \text { ribu }\end{array}$ & $\begin{array}{l}\text { keluarga (KK) di wilayah eksisting didominasi } \\
\text { oleh wiraswasta/pengusaha dan di wilayah }\end{array}$ \\
\hline $\begin{array}{l}\text { Konsumsi air } \\
\text { PDAM/Bulan }\end{array}$ & $21-25 \mathrm{m3}$ & $21-25 \mathrm{m3}$ & $\begin{array}{l}\text { bangunan tempat tinggal pelanggan rumah } \\
\text { tangga menengah ke atas di kedua wilayah } \\
\text { didominasi oleh tipe bangunan yang cukup luas } \\
\text { yaitu }>120 \mathrm{~m}^{2} \text {. Hal ini jelas menunjukkan bahwa } \\
\text { rumah tangga tersebut benar-benar termasuk } \\
\text { kategori pelanggan PDAM menengah ke atas } \\
(\mathrm{R} 6-\mathrm{R} 8) \text {. }\end{array}$ \\
\hline
\end{tabular}

Sumber: Analisis Penulis, 2015

Analisis Penilaian Kepuasan Pelanggan dan Penerapan Pelayanan Air Minum PDAM di Wilayah Eksisting ZAMP dan Taman Yasmin

\section{Penilaian Kepuasan Pelanggan}

Penilaian kepuasan pelanggan pada wilayah eksisting ZAMP dilakukan terhadap 96 sampel responden yang terdiri dari 65 responden rumah tangga menengah (R3-R5) dan 31 responden rumah tangga menengah ke atas (R6-R8). Seperti yang telah disebutkan sebelumnya, aspek yang dinilai untuk mengetahui kepuasan pelanggan tersebut terdiri dari kualitas air, kuantitas debit air, kontinuitas aliran air dan komunikasi PDAM. Berikut ini merupakan hasil skoring dari masing-masing aspek tersebut:

TABEL 3

KEPUASAN PELANGGAN TERHADAP KUALITAS, KUANTITAS, KONTINUITAS AIR DAN KOMUNIKASI PDAM DI WILAYAH EKSISTING ZAMP

\begin{tabular}{|c|l|c|c|}
\hline \multirow{2}{*}{ No } & \multirow{2}{*}{ Komponen Penilaian } & \multicolumn{2}{|c|}{ Jenis Pelanggan Rumah Tangga (RT) } \\
\cline { 3 - 4 } & & RT Menengah (R3-R5) & RT Menengah ke Atas (R6-R8) \\
\hline 1 & Kualitas Air & 3.87 & 3.91 \\
\hline \multirow{2}{*}{} & - Kejernihan & 3.92 & 3.90 \\
& - Bau & 3.85 & 3.90 \\
& - Rasa & 3.78 & 3.84 \\
& - Warna & 3.91 & 4.00 \\
\hline \multirow{2}{*}{2} & Kuantitas Air & 3.74 & 3.68 \\
\hline \multirow{2}{*}{3} & Kontinuitas Air & 3.80 & 3.65 \\
\hline 4 & Komunikasi PDAM & $\mathbf{2 . 5 0}$ & $\mathbf{2 . 5 4}$ \\
\hline \multirow{2}{*}{ - Penyampaian Informasi } & 2.46 & 2.55 \\
& Oleh PDAM & & \\
& Tingkat Kepercayaan & 2.54 & 2.52 \\
\hline
\end{tabular}

Sumber: Analisis Penulis, 2015

Keterangan: Skor

(4.00 - 3.25: Baik) (3.24 - 2.50: Cukup) $\quad(2.49-1.75:$ Kurang Baik) $\quad(1.74-1.00:$ Buruk)

Pada wilayah Perumahan Taman Yasmin, kepuasan pelanggan PDAM dinilai dari hasil survei terhadap 42 sampel responden. Masing-masing kategori pelanggan rumah tangga menengah (R3-R5) dan menengah ke atas (R6-R8) terdiri dari 21 responden. Berikut merupakan hasil analisis skoring kepuasan pelanggan tersebut: 
JPWK 11 (4) Nurul Ainy Gumilar Kajian Strategi Pengembangan Zona Air Minum Prima (Zamp) Pada Kelompok Pelanggan Rumah Tangga Di Kota Bogor

TABEL 4

KEPUASAN PELANGGAN TERHADAP KUALITAS, KUANTITAS, KONTINUITAS AIR DAN KOMUNIKASI PDAM DI WILAYAH TAMAN YASMIN

\begin{tabular}{|c|c|c|c|}
\hline \multirow{2}{*}{ No } & \multirow{2}{*}{ Komponen Penilaian } & \multicolumn{2}{|c|}{ Jenis Pelanggan Rumah Tangga (RT) } \\
\hline & & RT Menengah (R3-R5) & RT Menengah ke Atas (R6-R8) \\
\hline \multirow[t]{5}{*}{1} & Kualitas Air & 3.73 & 3.72 \\
\hline & - Kejernihan & 3.62 & 3.67 \\
\hline & $-\mathrm{Bau}$ & 3.76 & 3.67 \\
\hline & - Rasa & 3.76 & 3.62 \\
\hline & - Warna & 3.76 & 3.90 \\
\hline 2 & Kuantitas Air & 3.43 & 3.29 \\
\hline 3 & Kontinuitas Air & 3.57 & 3.52 \\
\hline 4 & Komunikasi PDAM & 2.72 & 2.43 \\
\hline & $\begin{array}{l}\text { Penyampaian Informasi } \\
\text { oleh PDAM }\end{array}$ & 2.57 & 2.29 \\
\hline & $\begin{array}{l}\text { - Tingkat Kepercayaan } \\
\text { Pelanggan pada PDAM }\end{array}$ & 2.86 & 2.57 \\
\hline
\end{tabular}

Sumber: Analisis Penulis, 2015

Keterangan: Skor
(4.00-3.25: Baik)
(3.24 - 2.50: Cukup)
(2.49 - 1.75: Kurang Baik)
(1.74 - 1.00: Buruk)

Hasil penilaian kepuasan pelanggan di kedua wilayah menunjukkan bahwa pada aspek kualitas, kuantitas dan kontinuitas air dinilai "baik" oleh pelanggan rumah tangga. Akan tetapi aspek komunikasi PDAM tidak menunjukkan hasil yang cukup baik. Penilaian terhadap aspek komunikasi PDAM untuk RT menengah "cukup baik" sedangkan pada RT menengah ke atas memiliki skor yang cukup rendah yaitu 2,43 sehingga masuk dalam penilaian "kurang baik".

\section{Penerapan Air Siap Minum di Wilayah Eksisting ZAMP}

Dari hasil survei terhadap 96 sampel responden pelanggan rumah tangga yang diambil pada wilayah eksisting ZAMP di Kecamatan Bogor Selatan dan Bogor Timur, terdapat 64 orang responden atau $67 \%$ yang sudah mengetahui mengenai air siap minum dan Zona Air Minum Prima (ZAMP). Dari 64 responden pelanggan rumah tangga yang sudah mengetahui tentang air siap minum dan ZAMP tersebut, terdapat 33 responden atau $52 \%$ yang menggunakan PDAM sebagai sumber air minum rumah tangga. Sedangkan sisanya sebanyak 31 responden atau 48\% memilih untuk menggunakan galon isi ulang atau Air Minum Dalam Kemasan (AMDK) untuk konsumsi air minum rumah tangganya.

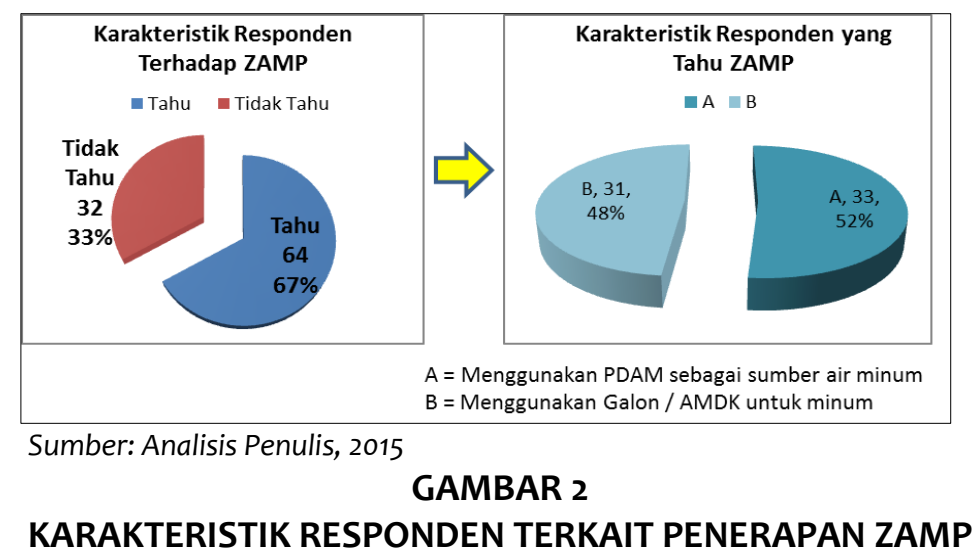


Nurul Ainy Gumilar | Kajian Strategi Pengembangan Zona Air Minum Prima (Zamp) Pada Kelompok Pelanggan Rumah Tangga Di Kota Bogor

JPWK 11 (4)

Dari 52\% responden pelanggan rumah tangga yang menggunakan air PDAM sebagai sumber air minum di wilayah eksisting ZAMP, dibagi kedalam tiga metode penggunaan, yaitu diminum langsung, dimasak terlebih dahulu dan memakai water purifier. Berdasarkan hasil survei terhadap ketiga metode tersebut, terdapat $43 \%$ pelanggan yang sudah menggunakan sebagai air minum langsung. Sedangkan dari 48\% pelanggan tidak memakai air siap minum PDAM, sebanyak 32\% beralasan bahwa mereka masih tidak yakin pipa PDAM yang digunakan steril untuk menyalurkan air siap minum langsung ke sambungan rumah pelanggan.
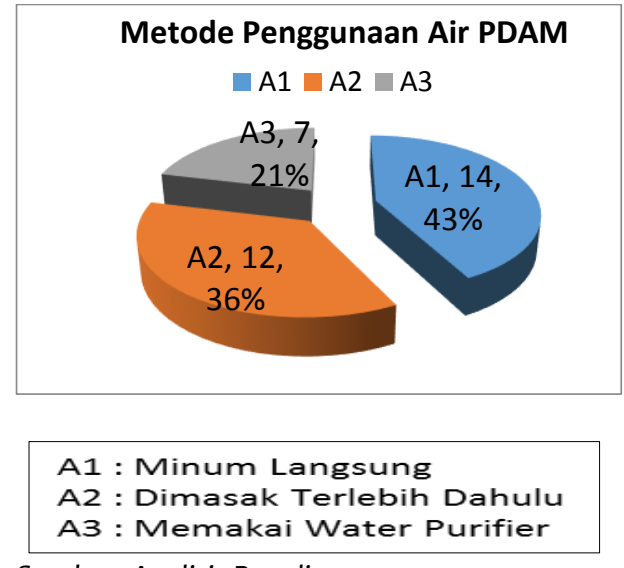

Sumber: Analisis Penulis, 2015

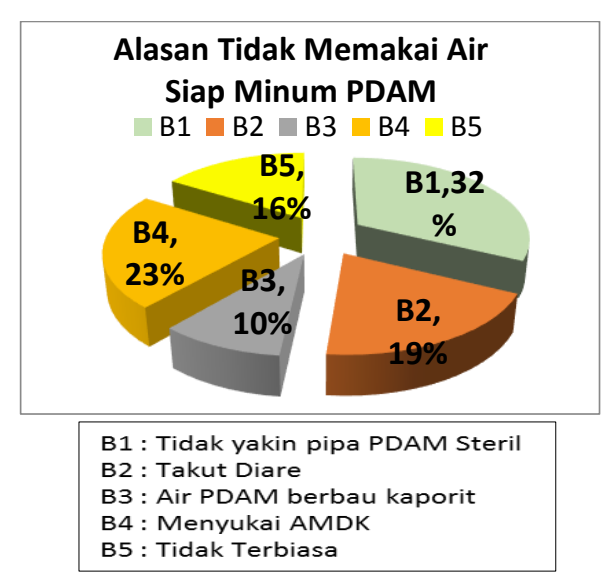

\section{METODE PENGGUNAAN DAN ALASAN TIDAK MENGGUNAKAN AIR SIAP MINUM}

Rendahnya penerapan air siap minum pada pelanggan rumah tangga di wilayah eksisting ZAMP tersebut diduga memiliki keterkaitan dengan rendahnya penilaian kepuasan pelanggan terhadap aspek komunikasi PDAM seperti yang telah dijelaskan pada sub-bab sebelumnya. Penilaian pelanggan di wilayah eksisting ZAMP terhadap informasi yang disampaikan oleh PDAM dan tingkat kepercayaan pelanggan terhadap PDAM masih cukup rendah yaitu 2,51 dan 2,53 (berada di batas bawah kategori cukup baik : 2,50). Oleh karena itu diperlukan sosialisasi lebih lanjut untuk pengembangan penerapan ZAMP di wilayah eksisting.

\section{Analisis Willingness to Pay (WTP) Pelanggan dan Rencana Pengembangan ZAMP pada Wilayah Perumahan Taman Yasmin}

Dari hasil perhitungan WTP, diperoleh besarnya nilai rata-rata WTP pada wilayah eksisting ZAMP adalah Rp 396/ $\mathrm{m}^{3}$. Rendahnya nilai WTP tersebut dikarenakan pada pelanggan rumah tangga menengah (R3-R5) lebih banyak yang memilih untuk memberikan kenaikan imbalan hanya sebesar Rp 250/m³. Dengan demikian, dapat disimpulkan bahwa pelanggan rumah tangga di wilayah eksisting ZAMP bersedia untuk memberikan imbalan lebih atas manfaat air siap minum yang diterimanya (kenaikan harga/tarif air minum) yaitu maksimal sebesar $\mathrm{Rp} 396 / \mathrm{KK} / \mathrm{m}^{3}$. Sedangkan dari hasil survei terhadap 42 sampel responden pelanggan rumah tangga di Perumahan Taman Yasmin, terdapat 95\% responden yang memiliki respon positif terhadap rencana penerapan air siap minum dan pengembangan Zona Air Minum Prima (ZAMP) dengan nilai rataan WTP yang lebih besar yaitu Rp. $518 / \mathrm{KK} / \mathrm{m}^{3}$.

Persamaan regresi linier dari Willingness to Pay (WTP) pelanggan PDAM untuk pengembangan ZAMP menggunakan faktor-faktor yang mempengaruhi besarnya WTP responden dengan asumsi yang diperoleh dari studi-studi terdahulu yang pernah dilakukan terkait air siap minum adalah sebagai berikut:

$$
Y=-57+0,56 X_{1}-107 X_{2}+90,9 X_{3}+63 X_{4}+24,5 X_{5}
$$


JPWK 11 (4) Nurul Ainy Gumilar | Kajian Strategi Pengembangan Zona Air Minum Prima (Zamp) Pada Kelompok Pelanggan Rumah Tangga Di Kota Bogor

dengan :

$\mathrm{Y}=$ WTP (Rupiah),

$\mathrm{X}_{1}=$ Umur (tahun),

$\mathrm{X}_{2}=$ Pendidikan (satuan kategori $1=\mathrm{SD}$ s.d 6 = doktor),

$\mathrm{X}_{3}=$ Pendapatan (satuan kategori $1=\leq 1,5$ juta $\mathrm{s} . \mathrm{d} 7=>10$ juta),

$\mathrm{X}_{4}=$ Kualitas Air (\%, nilai persen diperoleh dengan menjumlahkan seluruh nilai kualitas air lalu dibagi 16), dan

$\mathrm{X}_{5}=$ Banyak Air $\left(\mathrm{m}^{3}\right)$

Hipotesis :

$\mathrm{H}_{0}: \beta_{1}=\beta_{2}=\ldots=\beta_{5}=0$ (peubah respon (WTP) tidak mempunyai hubungan linier dengan peubah penjelas (Umur - Banyak Air))

$\mathrm{H}_{1}$ : minimal ada satu $\beta_{\mathrm{j}} \neq 0, j=1,2, \ldots, 5$ (peubah respon (WTP) mempunyai hubungan linier dengan minimal 1 peubah penjelas)

Dari hasil uji F, nilai P value $=0<0.05$ maka tolak Ho. Dengan demikian berarti minimal ada satu peubah penjelas yang berhubungan linier dengan WTP. Sedangkan hasil uji-t menunjukkan terdapat tiga peubah respon yang mempunyai hubungan linier dengan WTP yaitu Pendidikan, Pendapatan dan Banyak Air karena ketiga nilai p-value mereka $<0.05$ sehingga tolak $\mathrm{H}_{\mathrm{o}}$. Akan tetapi hasil uji dari variabel pendidikan walaupun berpengaruh nyata tetapi memiliki nilai koefisien yang negatif (tabel 6). Dengan demikian, variabel pendidikan tidak dapat menjelaskan dengan tepat pengaruh terhadap WTP. Hasil analisis regresi linier berganda tersebut cukup baik karena diperoleh nilai $\mathrm{R}^{2}$ yang besar yaitu $72,3 \%$.

TABEL 5. HASIL OLAH DATA UNTUK UJI-t

The regression equation is

WTP $=-57$ + 0,56 Umur - 107 Pendidikan + 90,9 Pendapatan + 63 Kualitas Air + 24,5 Banyak Air

\begin{tabular}{|l|c|c|c|c|c|}
\hline Predictor & Coef & SE Coef & T & P & VIF \\
\hline Constant & $-56,7$ & 277,1 & $-0,20$ & 0,839 & \\
\hline Umur & 0,560 & 1,820 & 0,31 & 0,760 & 1,135 \\
\hline Pendidikan & $-107,20$ & 37,19 & $-2,88$ & 0,007 & 1,716 \\
\hline Pendapatan & 90,94 & 17,22 & 5,28 & 0,000 & 1,841 \\
\hline Kualitas Air & 62,6 & 256,1 & 0,24 & 0,808 & 1,134 \\
\hline Banyak Air & 24,455 & 5,504 & 4,44 & 0,000 & 1,501 \\
\hline
\end{tabular}

Sumber: Output Minitab, 2015

\section{RUMUSAN STRATEGI}

Selain penggunaan air siap minum yang masih rendah di wilayah eksisting ZAMP, terdapat beberapa permasalahan lain yang dapat diidentifikasi berdasarkan hasil temuan studi ini yaitu rendahnya penilaian pelanggan rumah tangga baik di wilayah eksisting ZAMP maupun wilayah perencanaan (Taman Yasmin) terhadap aspek komunikasi PDAM dan rendahnya pengembangan ZAMP ke wilayah rencana pengembangan di Zona 4 PDAM (area Kecamatan Bogor Barat). Oleh karena itu, diperlukan adanya rumusan strategi-strategi yang dapat mengatasi permasalahan-permasalahan tersebut, antara lain sebagai berikut: 
Nurul Ainy Gumilar | Kajian Strategi Pengembangan Zona Air Minum Prima (Zamp) Pada Kelompok Pelanggan Rumah Tangga Di Kota Bogor

Tabel 6

Rumusan Strategi Pengembangan ZAMP Pelanggan Rumah Tangga di Kota Bogor

\begin{tabular}{|c|c|c|c|}
\hline No & Aspek & Jenis Strategi & Penjelasan \\
\hline \multirow{2}{*}{1} & \multirow{2}{*}{ Komunikasi } & $\begin{array}{l}\text { Sosialisasi } \\
\text { Awal } \\
\text { (Penyuluhan } \\
\text { Umum) }\end{array}$ & $\begin{array}{l}\text { Untuk pelanggan rumah tangga di wilayah eksisting ZAMP dan } \\
\text { rencana pengembangan (Taman Yasmin) yang masih belum } \\
\text { mengetahui sama sekali tentang adanya program ZAMP. } \\
\text { Beberapa media yang dapat mengakomodasi adalah media cetak, } \\
\text { media elektronik, media sosial dan surat pemberitahuan. }\end{array}$ \\
\hline & & $\begin{array}{l}\text { Sosialisasi } \\
\text { Lanjutan } \\
\text { (Pendalaman) }\end{array}$ & $\begin{array}{l}\text { Bagi pelanggan rumah tangga di wilayah eksisting ZAMP yang } \\
\text { sudah mengetahui air siap minum ttapi belum menggunakannya } \\
\text { untuk minum langsung dan yang lebih memilih menggunakan air } \\
\text { galon isi ulang/AMDK. Dilakukan melalui media kelompok, } \\
\text { kunjungan (door to door) dan kampanye air siap minum. }\end{array}$ \\
\hline 2 & Harga & $\begin{array}{l}\text { Penyesuaian } \\
\text { Harga/Tarif Air } \\
\text { Siap Minum }\end{array}$ & $\begin{array}{l}\text { Dilakukan dengan membedakan antara tarif pelanggan PDAM } \\
\text { biasa dan tarif air siap minum yang dikenakan pada pelanggan } \\
\text { rumah tangga di wilayah eksisting ZAMP dan Taman Yasmin (hasil } \\
\text { WTP:Rp } 396 / \mathrm{KK} / \mathrm{m}^{3} \text { dan Rp } 518 / \mathrm{KK} / \mathrm{m}^{3} \text { ) }\end{array}$ \\
\hline 3 & Fisik & $\begin{array}{l}\text { Penawaran } \\
\text { Pemasangan } \\
\text { filter air } \\
\text { tambahan }\end{array}$ & $\begin{array}{l}\text { PDAM menawarkan jasa pemasangan filter air kepada pelanggan } \\
\text { rumah tangga yang bersifat opsional agar secara psikologis } \\
\text { pelanggan merasa lebih nyaman dan tidak ragu-ragu lagi untuk } \\
\text { mengkonsumsi air minum secara langsung (potable water). }\end{array}$ \\
\hline
\end{tabular}

Sumber: Analisis Penulis, 2015

\section{KESIMPULAN DAN SARAN}

Baik Pelanggan PDAM rumah tangga menengah (R3-R5) maupun rumah tangga menengah ke atas (R6-R8) di wilayah eksisting ZAMP dan wilayah rencana pengembangan Taman Yasmin memiliki kesamaan karakteristik meliputi jumlah anggota keluarga, tingkat pendidikan terakhir kepala keluarga, pekerjaan kepala keluarga rata-rata, penghasilan rumah tangga/bulan rata-rata, luas bangunan tempat tinggal dan konsumsi air PDAM/bulan. Oleh karena itu dapat disimpulkan bahwa secara karakteristik pelanggan untuk rumah tangga di wilayah Perumahan Taman Yasmin memiliki potensi untuk pengembangan air siap minum seperti pada pelanggan rumah tangga di wilayah eksisting Zona Air Minum Prima (ZAMP). Wilayah rencana pengembangan ZAMP di Taman Yasmin yang dinilai potensial meliputi sektor 1, 2, 3, 5 dan 7. Hasil survei terhadap pelanggan rumah tangga di wilayah perencanaan tersebut menunjukkan tanggapan positif dari masyarakat sekitar. Sebesar $95 \%$ responden rumah tangga bersedia untuk menerima rencana pengembangan air siap minum di wilayahnya.

Secara keseluruhan kepuasan pelanggan rumah tangga terhadap aspek kualitas, kuantitas dan kontinuitas air PDAM di wilayah eksisting ZAMP lebih besar jika dibandingkan dengan Taman Yasmin. Sedangkan penilaian terhadap aspek komunikasi pelanggan PDAM di kedua wilayah tersebut masih kurang baik. Hal ini terlihat dari hasil penilaian kepuasan pelanggan terhadap informasi yang disampaikan oleh PDAM dinilai masih kurang/rendah. Dari hasil evaluasi penerapan air siap minum di wilayah eksisting ZAMP, sebesar $67 \%$ responden sudah mengetahui tentang air siap minum (program ZAMP). Dari yang sudah mengetahui program ZAMP tersebut, sekitar 52\% menggunakan air PDAM sebagai sumber untuk minum dan 48\% masih menggunakan 
JPWK 11 (4) Nurul Ainy Gumilar | Kajian Strategi Pengembangan Zona Air Minum Prima (Zamp) Pada Kelompok Pelanggan Rumah Tangga Di Kota Bogor

air galon isi ulang/air minum dalam kemasan (AMDK). Dengan demikian jumlah pelanggan rumah tangga yang benar-benar mengkonsumsi langsung air siap minum PDAM (program ZAMP) masih rendah/sedikit. Selain itu, pelanggan yang enggan mengkonsumsi air siap minum sebagian besar (32\%) beralasan bahwa mereka masih tidak yakin pipa PDAM yang digunakan tersebut steril untuk mengalirkan air siap minum sampai ke sambungan kran rumah tangga.

Di wilayah eksisting ZAMP sebanyak 52 responden dari 96 sampel responden rumah tangga yang diambil atau sebesar 54\% bersedia memberikan imbalan lebih (membayar kenaikan tarif/harga) untuk air siap minum dengan nilai Willingness to Pay (WTP) sebesar Rp 396/KK/m3. Sedangkan di perumahan Taman Yasmin sekitar 90\% dari sampel responden memiliki keinginan untuk membayar lebih terhadap peningkatan kualitas air siap minum dengan nilai WTP sebesar Rp. $518 / \mathrm{KK} / \mathrm{m} 3$. Dari hasil analisis regresi terhadap faktor-faktor yang mempengaruhi besarnya nilai WTP tersebut diperoleh bahwa variabel pendapatan dan banyaknya air (jumlah air) yang dikonsumsi memiliki pengaruh yang signifikan terhadap WTP. Adapun dari model regresi yang digunakan diperoleh nilai $\mathrm{R}^{2}$ yang cukup baik yaitu $72,3 \%$. Nilai $\mathrm{R}^{2}$ tersebut menunjukkan bahwa keragaman yang dapat dijelaskan oleh model adalah sebesar $72,3 \%$ sedangkan sisanya sebesar $27,7 \%$ dijelaskan oleh faktor-faktor lainnya yang berada di luar model.

Berdasarkan hasil analisis yang telah dilakukan terhadap karakteristik pelanggan, kepuasan pelanggan, evaluasi penerapan ZAMP dan willingness to pay (kesediaan membayar) dapat dirumuskan beberapa strategi untuk pengembangan ZAMP di Kota Bogor. Beberapa strategi yang dapat direkomendasikan dari hasil penelitian ini meliputi strategi komunikasi melalui sosialisasi awal dan lanjutan, strategi penyesuaian harga atau tarif air siap minum dan strategi pemasangan filter air tambahan pada kran rumah tangga.

\section{DAFTAR PUSTAKA}

Asghara, A. (2007). Strategi Peningkatan Kapasitas Pelayanan Air Bersih Di Kota Bangko Kabupaten Merangin. Tesis. Universitas Diponegoro, Semarang.

Corporate Plan PDAM Tirta Pakuan Kota Bogor 2013-2017. PDAM Tirta Pakuan Kota Bogor bekerjasama dengan IUWASH.

Fajdawani, A.K. (2009). Strategi Pengembangan Zonasi Air Minum (Studi Kasus di PDAM Tirta Pakuan Kota Bogor). Tesis. Institut Pertanian Bogor, Bogor.

Haq. M, Mustafa. U, Ahmad. I. (2008). "Household's Willingness to Pay for Safe Drinking Water: A Case Study of Abbottabad District". MPRA Paper, No. 15208, posted 14 May 2009.

Irawan, B.B. (2009). "Willingness To Pay dan Ability To Pay Pelanggan Rumah Tangga sebagai Respon Terhadap Pelayanan Air Bersih dari PDAM Kota Surakarta". JEJAK, Vol. 2, No. 1, Maret, Hal. 29-43.

Jain, S.K dan Singh. V.P. (2003). Development in Water Science : Water Resources Systems Planning and Management. Amsterdam: Elsevier Science BV.

Joko, T. (2010). Unit Air Baku dalam Sistem Penyediaan Air Minum. Yogyakarta: Graha Ilmu.

Khan. H, Iqbal. F, Saeed. I, Khan. I. (2010). "Estimating Willingness to Pay for Improvements in Drinking Water Quality : Evidence from Peshawar, Northern Pakistan, Pakistan". Environmental Economics, Volume I, Issue 2.

Natalia. B.M, Mardiyono, Said. A. (2014). "Implementasi Program Zona Air Minum Prima (ZAMP) untuk Memenuhi Kebutuhan Air Minum Masyarakat (Studi pada PDAM Kota Malang)". Jurnal Administrasi Publik (JAP), Vol. 2, No. 1, Hal. 11-15.

Nazir, M. (2011). Metode Penelitian. Jakarta: Ghalia Indonesia.

Sarwono, Jonathan. (2006). Metode Penelitian Kuantitatif dan Kualitatif. Yogyakarta: Graha Ilmu. 
Nurul Ainy Gumilar | Kajian Strategi Pengembangan Zona Air Minum Prima (Zamp) Pada Kelompok Pelanggan Rumah Tangga Di Kota Bogor

JPWK 11 (4)

Simanjuntak, G.E.M. (2009). Analisis Willingness To Pay Masyarakat terhadap Peningkatan Pelayanan Sistem Penyediaan Air Bersih dengan WSLIC (Water Sanitation for Low Income Community). Skripsi. Institut Pertanian Bogor, Bogor.

Sugiyono. 2008. Statistika untuk Penelitian. Bandung : Alfabeta.

Survey Kepuasan Pelanggan PDAM Tirta Pakuan Kota Bogor Tahun 2012. Kerjasama PDAM Tirta Pakuan Kota Bogor dan Pusat Studi Pembangunan Pertanian dan Pedesaan Institut Pertanian Bogor.

Tjiptono. F, Anastasia D. (2003). Total Quality Management. Yogyakarta : ANDI. 